\title{
Perdarahan saluran cerna setelah dilakukan intervensi koroner perkutan: suatu keputusan terapi yang sulit
}

\author{
Meidianaser Putra ${ }^{1}$, Muhammad Fadil ${ }^{2}$, Yose Ramda Ilhami \\ 1. RSI Ibnu Sina, Padang; 2. Bagian Kardiologi dan Kedokteran Vaskular, Fakultas Kedokteran, \\ Universitas Andalas
}

Korespondensi: Meidianaser Putra, email: dr.mediputra@gmail.com

\begin{abstract}
Abstrak
Intervensi koroner perkutan merupakan prosedur invasif jantung yang sering dilakukan untuk mengobati pasien dengan penyakit arteri koroner. Komplikasi yang menakutkan seperti diseksi koroner atau penyumbatan koroner akut pada era balon angioplasti telah banyak berkurang dengan ditemukannya stent arteri koroner dan penggunaan rutin terapi antiplatelet dan antitrombotik. Peningkatan penggunaan DAPT tersebut meningkatkan risiko pasien untuk terjadinya cedera saluran cerna dan perdarahan. Mengobati pasien yang mengalami perdarahan setelah IKP merupakan suatu hal yang rumit, karena kita harus mempertimbangkan intervensi yang tepat untuk mengelola perdarahan aktif, untuk menimbang manfaat potensial untuk meneruskan atau menghentikan terapi antiplatelet dan untuk mengevaluasi apakah diperlukan transfusi sel darah merah yang bisa menimbulkan efek samping yang merugikan. Pemberian PPI direkomendasikan oleh panduan Amerika dan Eropa untuk terapi yang bisa diberikan pada perdarahan saluran cerna akibat pemberian antiplatelet dan hemostasis endoskopi merupakan pilihan yang direkomendasikan untuk mengurangi angka morbiditas dan mortalitas

Kata kunci: Intervensi koroner perkutan; perdarahan saluran cerna; antiplatelet; penghambat pompa proton
\end{abstract}

\begin{abstract}
Percutaneous coronary intervention $(P C I)$ is the most common cardiac invasive procedure to treat patients with coronary artery disease. Fearsome complications such as coronary dissection or acute vessel closure in the balloon angioplasty era have been largely mitigated with the introduction of coronary artery stents and the routine use of antiplatelet and antithrombotic therapy. The increased use of DAPT will increasing the patient's risk for gastrointestinal injury and bleeding. Treating patients who have bleeding after $\mathrm{PCl}$ is complicated, because we must consider appropriate interventions to manage active bleeding, considering the potential benefits of continuing or stopping antiplatelet therapy and to evaluate whether PRC transfusions are needed that can have side effects disadvantageous. Giving PPIs was recommended by American and European guidelines for therapies that can be given to gastrointestinal bleeding due to antiplatelet administration and endoscopic homeostasis are recommended options for reducing morbidity and mortality.
\end{abstract}

Keywords: percutaneous coroner intervention; gastrointestinal bleeding; antiplatelet; proton pump inhibitor 


\section{PENDAHULUAN}

Selama 20-30 tahun terakhir, terapi reperfusi telah mengurangi mortalitas yang terkait dengan IMA-EST. Menurut terapi antiplatelet terkini pada penelitian JAMI, IKP dilakukan untuk 97,2\% dari semua pasien IMA-EST, dengan tingkat kematian jantung di rumah sakit sebesar 3,2\%. Registri multisenter prospektif J-AMI mengindikasikan bahwa kejadian perdarahan adalah 1,58\%, dengan perdarahan saluran cerna menyumbang sekitar $30 \%$ dari semua komplikasi perdarahan. Secara global, terapi antiplatelet digunakan pada kondisi IKP primer untuk merawat pasien dengan IMA, dan telah terbukti mengurangi kejadian kardiovaskuler dan mencegah trombosis stent jangka pendek setelah IKP. Namun, terapi antiplatelet juga meningkatkan risiko komplikasi perdarahan pasca IKP. ${ }^{1}$ Pedoman bersama American College of Cardiology, American Heart Association, dan Society for Cardiovascular Angiography and Interventions merekomendasikan bahwa terapi aspirin harus dilanjutkan seumur hidup pada semua pasien dengan IMA-EST, dan clopidogrel atau prasugrel harus diberikan paling sedikit 12 bulan pada pasien yang menerima stent (BMS atau DES) selama IKP pada sindrom koroner akut. ${ }^{2}$

Kemajuan terapi antitrombotik telah memperbaiki hasil pasien yang menjalani IKP melalui penurunan kejadian iskemik dengan mengabaikan peningkatan komplikasi pendarahan terkait prosedur. Kejadian perdarahan mayor pada IKP cukup signifikan, dengan tingkat kejadian perdarahan 30 hari antara $0,7 \%$ dan $1,1 \%$ pada elektif, $0,6 \%$ dan $4,7 \%$ pada infark miokard akut non-ST elevasi, dan 0,9\% pada $8,9 \%$ pada infark miokard akut elevasi segmen ST, tergantung pada definisi yang digunakan. $^{3}$

Perdarahan merupakan komplikasi non kardiak yang paling umum terjadi pada IKP. Perdarahan postprosedural terjadi terkait dengan kematian jangka pendek dan jangka panjang, nonfatal infark miokard, stroke, transfusi darah, perawatan di rumah sakit yang berkepanjangan, rehospitalisasi, dan biaya rumah sakit yang meningkat. ${ }^{3,4}$ Endoskopi awal dianjurkan untuk kebanyakan pasien dengan perdarahan saluran cerna atas akut. Setelah hemostasis endoskopi berhasil, segera dimulakan kembali terapi antiplatelet dengan pemberian penghambat pompa proton (PPI) untuk mencegah kejadian iskemik lebih lanjut. Profilaksis PPI selama terapi antiplatelet mengurangi risiko perdarahan saluran cerna bagian atas. Interaksi metabolik potensial yang negatif antara PPI dan clopidogrel masih belum jelas. ${ }^{2}$

Beberapa penelitian sebelumnya yang telah melaporkan dampak prognostik perdarahan mayor tidak memperhitungkan perbedaan kovariat dasar seperti usia, tampilan klinis dan komorbiditas yang berdampak kepada angka KKM dan mortalitas. Sebaliknya, penelitian lain memiliki penyesuaian untuk kovariat awal, definisi yang berbeda tentang pendarahan utama seperti TIMI, 
GUSTO, STEEPLE, dan BARC telah digunakan, yang telah terbukti memiliki dampak berbeda pada hasil kematian/hasil KKM. Selanjutnya, waktu perdarahan dari prosedur indeks IKP yang termasuk dalam penelitian semacam itu bervariasi dari 48 jam, terbatas yang terjadi selama perawatan, hingga sampai 30 hari dengan dampak pada mortalitas dan hasil KKM yang dipelajari pada titik waktu yang berbeda seperti 30 hari, 6 bulan, atau 1 tahun.

Laporan kasus ini bertujuan untuk membahas tentang perdarahan saluran cerna setelah dilakukan intervensi koroner per kutan: suatu keputusan terapi yang sulit.

\section{LAPORAN KASUS}

Seorang pasien laki-laki usia 74 tahun datang ke IGD dengan keluhan nyeri dada khas infark sejak 1 jam sebelum masuk rumah sakit. Keluhan dirasakan terasa berat di dada dan menjalar ke punggung dengan durasi $>45$ menit disertai keringat dingin, mual dan muntah. Pasien tidak mengeluhkan sesak nafas serta tidak memiliki riwayat paroxysmal nocturnal dyspnoe, dyspnoe on the effort, maupun orthopnoe. Pasien tidak memiliki faktor risiko untuk penyakit jantung koroner seperti hipertensi, diabetes, merokok maupun dislipidemia. Pasien merupakan rujukan dari BMC dengan STEMI dan sudah mendapat terapi aspilet $160 \mathrm{mg}$ dan clopidogrel $300 \mathrm{mg}$. Pemeriksaan rekam jantung di BMC didapatkan gambaran AV blok derajat II tipe I dengan QRS rate 42 kali per menit, aksis normal, normal gelombang $P$ dengan $P R$ interval memanjang, durasi QRS $400 \mathrm{~ms}$, elevasi segmen ST 2-3 mm di II, III, aVF, dan depresi segmen ST di I, aVL, V1-V4, dan tidak dijumpai pembesaran jantung kiri ataupun kanan, QTc 339 ms (Gambar 1).

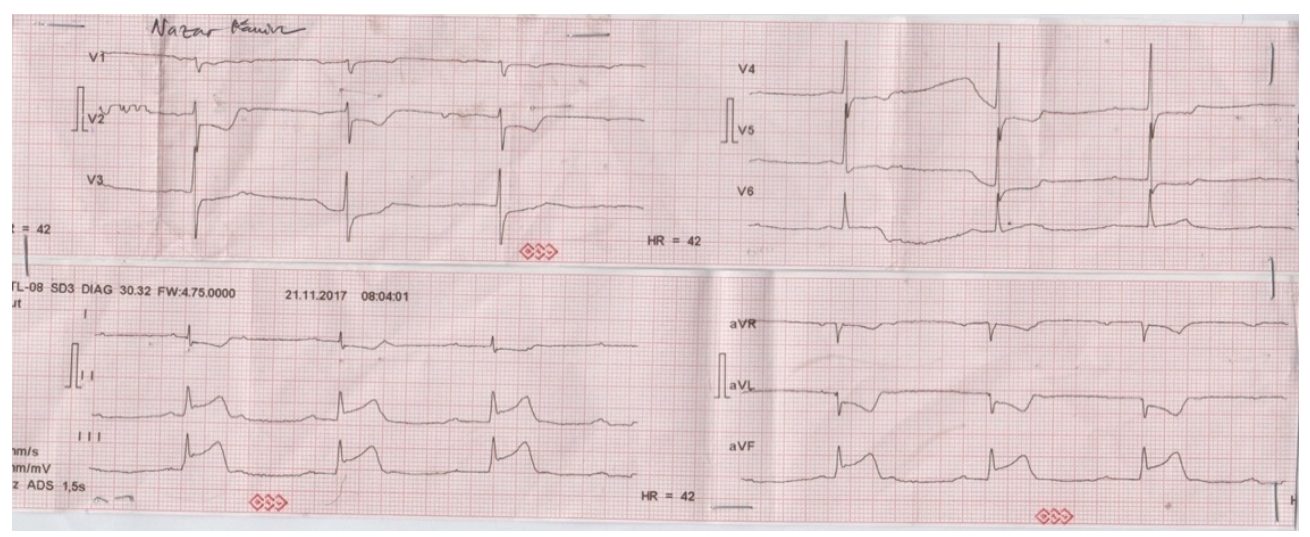

Gambar 1. Elektrokardiogram IGD RS BMC Padang

Pada saat sampai di IGD, pasien mengeluhkan nyeri dada dengan skala nyeri $8 / 10$ dan diikuti dengan kejang seluruh tubuh, EKG di monitor menunjukkan fibrilasi ventrikel. Segera dilakukan tindakan RJP dan setelah dilakukan RJP 2 siklus, pasien berhasil ROSC. Dari pemeriksaan fisik didapatkan tekanan darah 92/56, denyut nadi 45 kali per menit, pernafasan spontan 24 kali per 
menit, dan auskultasi paru tidak didapatkan rhonki ataupun wheezing. Dari rekaman EKG didapatkan gambaran irama junctional (Gambar 2). Pasien diberikan drip dopamine mulai $5 \mathrm{mcg} / \mathrm{kgBB} / \mathrm{l}$ dan direncanakan untuk dilakukan pemasangan alat pacu jantung sementara, tindakan IKP primer dan dirawat di CVCU, keluarga pasien setuju. Pasien diberikan loading untuk IKP primer dengan aspilet $160 \mathrm{mg}$ dan ticaglerol $180 \mathrm{mg}$. Pemeriksaan laboratorium didapatkan $\mathrm{Hb}$ $13,7 \mathrm{gr} / \mathrm{dl}$, leukosit 11.970/ $\mathrm{mm}^{3}$, hematokrit $41 \%$ dan trombosit $170.000 / \mathrm{mm}^{3}$, gula darah sewaktu 187 $\mathrm{mg} / \mathrm{dl}$, ureum $33 \mathrm{mg} / \mathrm{dl}$, kreatinin 1,5 $\mathrm{mg} / \mathrm{dl}$, CCT 39,3 $\mathrm{ml} / \mathrm{menit}$, natrium 141 $\mathrm{mmol} / \mathrm{L}$, kalium 3,1 mmol/L, kalsium 7,7 $\mathrm{mmol} / \mathrm{L}, \mathrm{HBsAg}$ non reaktif dan analisa gas darah didapatkan $\mathrm{pH} 7,29, \mathrm{pCO}_{2} 35, \mathrm{pO}_{2}$ $133 \mathrm{mmHg}, \mathrm{HCO}_{3}{ }^{-} 16,8 \mathrm{mmol} / \mathrm{L}, \mathrm{BE}-9,8$ $\mathrm{mmol} / \mathrm{L}$, Sat $\mathrm{O} 2$ 99\% dengan NRM $10 \mathrm{lpm}$. Pemeriksaan rontgen thoraks didapatkan CTR 50\%, segmen aorta dan pulmonal normal, apeks tertanam, pinggang jantung (+), tidak tampak infiltrat ataupun kranialisasi. Skor TIMI pada pasien ini didapatkan 3/14. Pasien didiagnosis dengan ROSC post VF ec ACS, STEMI akut Inferior onset 1 jam TIMI 3/14 pro revaskularisasi, dan irama AVB derajat II tipe I irama junctional rencana pemasangan pacu jantung sementara, AKI RIFLE R dd CKD stage III.

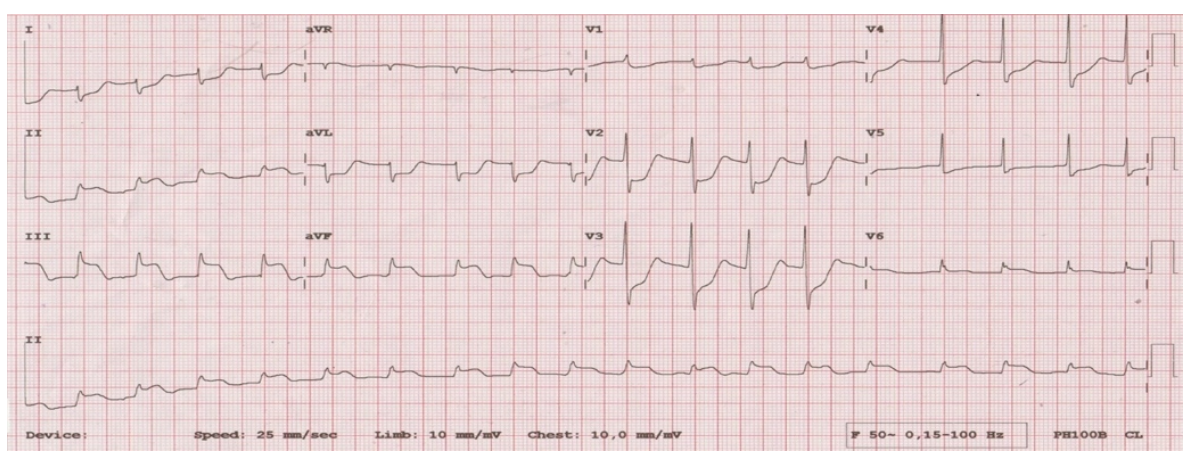

Gambar 2. Elektrokardiogram setting TPM 70/2/2 di CVCU RSUP Dr. M. Djamil

Pasien dilakukan pemasangan pacu jantung sementara dengan laju jantung 70 denyut per menit, output $2 \mathrm{~mA}$, sensitivitas $2 \mathrm{mV}$ dan dilakukan tindakan IKP primer dengan hasil pemasangan 1 stent DES di proksimal RCA pada CAD 3VD dengan hasil angiografi total oklusi di proksimal RCA dengan thrombus burden grade $V$, tidak terdapat masalah dan komplikasi selama tindakan (Gambar 3). Pasien diberikan terapi DAPT (aspilet dan ticaglerol) dosis tinggi. Skor CRUSADE pada pasien ini didapatkan 36 dengan risiko perdarahan sedang dan perkiraan angka perdarahan mayor dalam perawatan sebesar $8,6 \%$.

Di ruangan CVCU setelah tindakan, pasien mengeluhkan nyeri dada atipikal dan tampak NGT terpasang dengan residu berwarna coklat kehitaman. Pemeriksaan fisik didapatkan status hemodinamik stabil (Gambar 4). Pasien didiagnosis tambahan dengan stress ulcer ec post IKP dengan skor rockall 6, pasien dipuasakan dan diterapi dengan bolus lansoprazole $80 \mathrm{mg}$ 
dilanjutkan dengan drip $8 \mathrm{mg} / \mathrm{jam}$, sukralfat $3 \times 10 \mathrm{cc}$, DAPT tunda serta dilakukan gastric cooling setiap 4 jam. Laboratorium setelah tindakan didapatkan hemoglobin $13,4 \mathrm{mg} / \mathrm{dl}$, leukosit $13.740 / \mathrm{mm}^{3}$, hematokrit $40 \%$, trombosit $160.000 / \mathrm{mm}^{3}$, ureum $33 \mathrm{mg} / \mathrm{dl}$, kreatinin $1,5 \mathrm{mg} / \mathrm{dl}$.

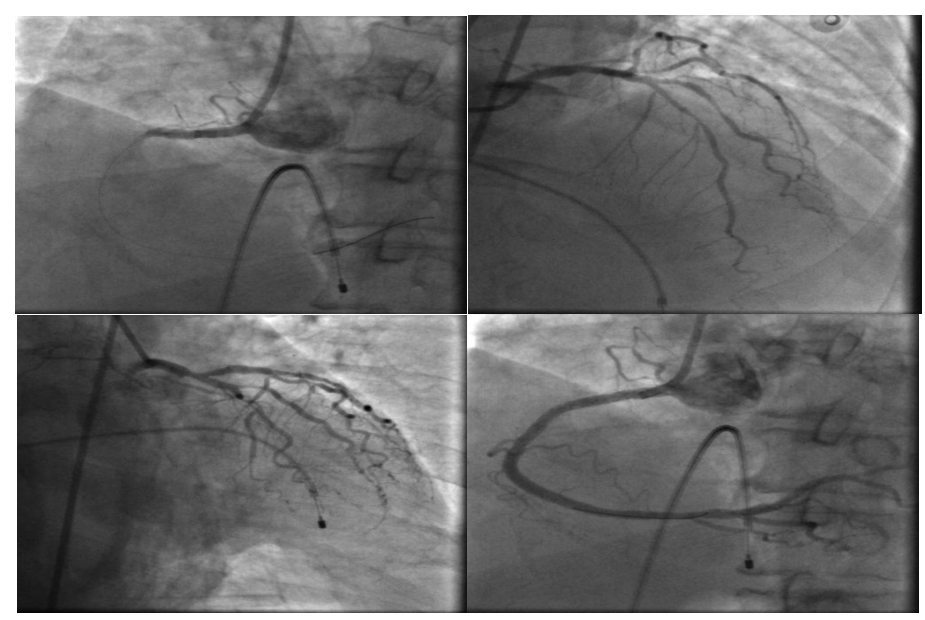

Gambar 3. Angiogram pre dan post IKP

Rawatan hari ke-2 di CVCU, pasien masih mengeluhkan nyeri dada post RJP, tampak terpasang NGT dengan residu berwarna coklat kehitaman $\pm 100 \quad \mathrm{cc} /$ siklus. Hemodinamik stabil dengan tekanan darah 128/66 mmHg, denyut nadi 72 kali per menit. Dilakukan konsultasi ke bagian Gizi Klinik untuk pemberian diet pada pasien dan dianjurkan untuk pemberian nutrisi parenteral total dengan kabiven peripheral $1440 \mathrm{ml}$ selama 18 jam banding dengan triofusin $500 \mathrm{ml}$ selama 6 jam, bila residu NGT <100 cc/4 jam dan atau tidak berwarna merah atau hitam, mulai diberikan gut feeding D5\% $50 \mathrm{cc}$, bila residu minimal $<50 \mathrm{cc}$ tidak berwarna merah atau hitam, mulai diberikan peptamen 50 cc dan ditingkatkan bertahap. Dilakukan pemeriksaan ekokardiografi dengan hasil EF 35\% (simpson), akinetik inferolateral, inferior, anterolateral, apikolateral, anterior dengan segmen lain hipokinetik, RA-RV dilatasi, LVH konsentrik remodeling,
TR moderat karena uncoaptasi leaflet dengan dilatasi annulus dengan intermediate probability $\mathrm{PH}$, kontraktilitas RV menurun, dan hemodinamik didapatkan stroke volume $18,5 \mathrm{ml} /$ denyut, cardiac output 1,3 L/menit, SVR 4841 dynes $/ \mathrm{sec} / \mathrm{cm}^{3}$, eRAP $8 \mathrm{mmHg}$ (Gambar 5). Pemeriksaan laboratorium darah didapatkan total kolesterol $189 \mathrm{mg} / \mathrm{dl}$, HDL $45 \mathrm{mg} / \mathrm{dl}$, LDL $115 \mathrm{mg} / \mathrm{dl}$, trigliserida 144 $\mathrm{mg} / \mathrm{dl}$, kalium 5,3 mmol/L, magnesium 2,0 $\mathrm{mg} / \mathrm{dl}$, SGOT/SGPT 360/102 u/l, AGD arteri $\mathrm{pH} 7,32, \mathrm{pCO}_{2} 11, \mathrm{pO} 2129, \mathrm{HCO}_{3}^{-} 5,7, \mathrm{BE}-$ 20,4 , Sat $\mathrm{O}_{2} 99 \%$, dengan kesan asidosis metabolik terkompensasi sebagian, sehingga diberikan terapi oksigen dengan RM $10 \mathrm{lpm}$. Setelah NGT jernih dan skor rockal didapatkan 5, dimulai ticagleror dengan tetap memperhatikan tanda perdarahan yang bertambah, penyekat beta belum bisa diberikan sebagai antiaritmia post VT/VF karena cardiac output masih kecil, imidapril 2x5 mg, 
paracetamol 4x1 gr untuk nyeri di daerah dada post RJP dan pasien dilakukan pemasangan kateter vena sentral serta terapi lain dilanjutkan.

Rawatan hari ke-3, tampak NGT dengan residu minimal. Hemodinamik stabil dengan tekanan darah 138/68 $\mathrm{mmHg}$, denyut nadi 81 kali per menit. Pemeriksaan laboratorium didapatkan hemoglobin 13,5 $\mathrm{mg} / \mathrm{dl}$, leukosit $17.910 / \mathrm{mm}^{3}$, hematokrit $40 \%$, trombosit $140.000 / \mathrm{mm}^{3}$, ureum 67 $\mathrm{mg} / \mathrm{dl}$, kreatinin $1,7 \mathrm{mg} / \mathrm{dl}, A G D$ arteri didapatkan kesan asidosis metabolik terkompensasi, dan skor rockal didapatkan 5. Terapi diet pada pasien ditingkatkan dengan pemberian diet enteral peptamen $6 \times 200$ cc via NGT dan parenteral Triofusin E1000 500 cc via vena sentral. Pemberian drip lansoprazole dan terapi lainnya tetap dilanjutkan. Pasien dikonsulkan kebagian pulmonologi dengan hasil HAP dan mendapatkan terapi meropenem $3 \times 1 \mathrm{gr}$, levofloxacin $1 \times 750 \mathrm{mg}$, dan $n$-asetil sistein $2 \times 200 \mathrm{mg}$.

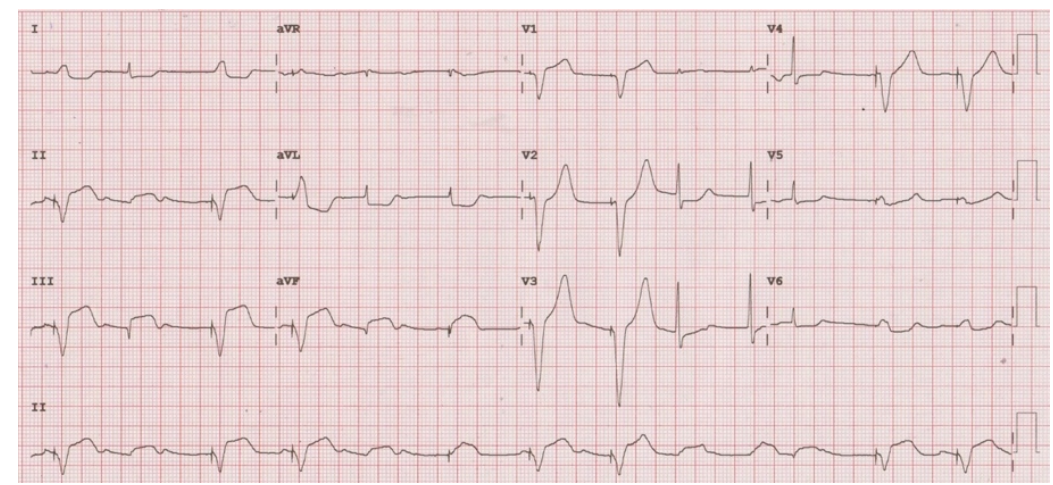

Gambar 4. Elektrokardigram setelah IKPP dan TPM

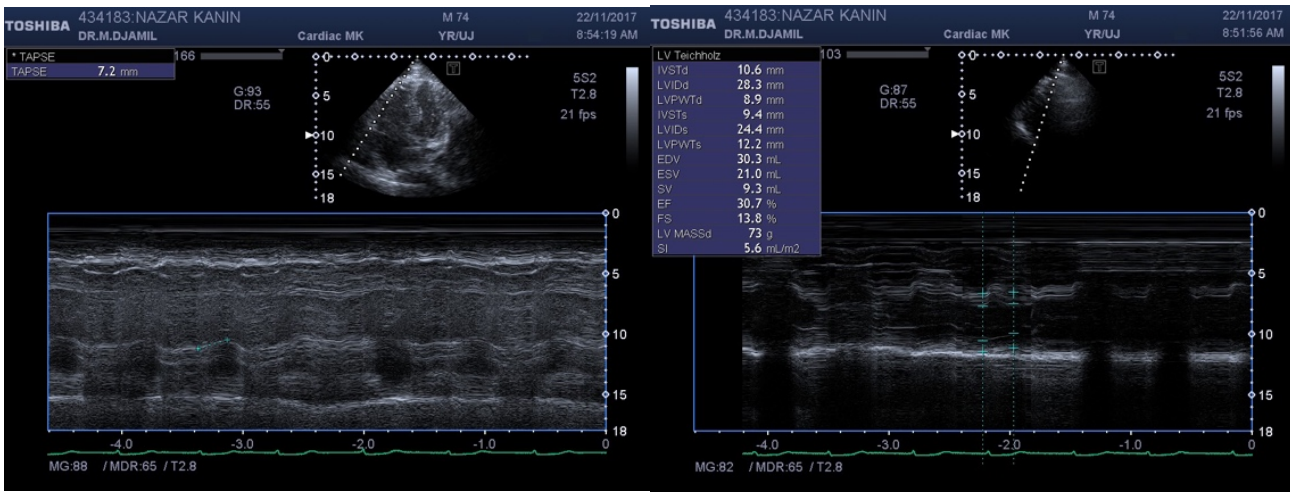

Gambar 5. Ekokardiogram

Rawatan hari ke-4, pasien mengeluhkan batuk dan sesak nafas, tampak residu di NGT berwarna hitam \pm 100 cc. Hemodinamik stabil dengan tekanan darah 142/85 mmHg, denyut nadi 80 kali per menit, saturasi $\mathrm{O}_{2} 99 \%$, CVP $18 \mathrm{mmHg}$, pemeriksaan fisik paru didapatkan ronkhi kasar di kedua lapangan paru dan jantung dalam batas normal. Pemeriksaan AGD pagi didapatkan kesan asidosis metabolik terkompensasi, dan skor rockal 6. Pasien dipuasakan sementara sampai residu $<100$ $\mathrm{ml}$ tidak berwarna hitam ataupun merah dan diberikan nutrisi parenteral total dengan kabiven perifer $1440 \mathrm{ml} / 18$ jam banding triofusin E1000 500 cc/6 jam 
sembari mengatasi perdarahan saluran cerna dengan drip lansoprazole dan ticaglerol ditunda, ditambahkan amiodaron $2 \times 200 \mathrm{mg}$ per oral sebagai antiaritmia post VT/VF (QTc $408 \mathrm{~ms}$ ). Jika residu jernih mulai diberikan gastric feeding dengan 50 cc D5\% dan ditingkatkan dengan pemberian nutrisi enteral peptamen mulai $50 \mathrm{cc}$ jika respon baik, dan terapi lain dilanjutkan. Pada sore hari pasien mengeluhkan sesak nafas, residu di NGT berwarna hitam. Hemodinamik didapatkan tekanan darah 103/49 mmHg, denyut nadi 72 kali per menit, laju nafas 24 kali per menit. Pemeriksaan fisik paru didapatkan ekspirasi memanjang, tidak ada rhonki dan wheezing. Pemeriksaan hematologi dan AGD ulang didapatkan hemoglobin 11,7 $\mathrm{gr} / \mathrm{dl}$, leukosit $14.350 / \mathrm{mm}^{3}$, hematokrit

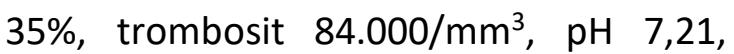
$\mathrm{pCO}_{2} 13, \mathrm{pO}_{2}$ 130, $\mathrm{HCO}_{3}^{-} 5,2$, BE -22,7, Sat $\mathrm{O}_{2}$ 98\% sehingga diberikan koreksi bicnat $200 \mathrm{mEq}$, persiapkan transfusi FFP 10 unit, diberikan nebu salbutamol ekstra dan cek $\mathrm{Hb}$ serial, AGD ulang post koreksi bicnat, cek ulang SGOT/SGPT serta konsul bagian penyakit dalam untuk trombositopenia dengan stress ulcer. Hasil konsul dari bagian penyakit dalam didapatkan sklera tidak ikterik, tampak spider nevi di daerah dada, tidak tampak eritema palmar ataupun kolateral vena dana sites, sehingga didiagnosis dengan hematemesis ec perdarahan nonvariceal ec stress ulcer dengan diagnosa diferensial perdarahan variceal ec sirosis hepatis, trombositopenia ec suspek ITP, AKI RIFLE R dan dianjurkan untuk pemberian $\mathrm{MC}$ diet liver $\mathrm{I}$, cek marker liver, cek marker perdarahan, USG abdomen serta pemberian drip lansoprazole hingga perdarahan berhenti. Setelah diberikan koreksi bicnat, pemeriksaan AGD ulang didapatkan $\mathrm{pH}$ 7,41, $\mathrm{pCO}_{2} 21, \mathrm{pO}_{2}$ 128, $\mathrm{HCO}_{3}^{-}$13,3, $\mathrm{BE}$ 11,3 , Sat $\mathrm{O}_{2} 99 \%$ dengan kesan perbaikan.

Rawatan hari ke-5, pasien masih mengeluhkan sesak nafas, residu NGT berwarna coklat $50 \mathrm{cc}$. Hemodinamik stabil dengan tekanan darah 129/66 mmHg, denyut nadi 68 kali per menit, laju nafas 22 kali per menit, sat $\mathrm{O}_{2} 99 \%$. Pasien masih didiagnosis kerja dengan ROSC post VT/VF, STEMI akut inferior onset 1 jam TIMI 3/14 post $\mathrm{PPCl} 1$ stent DES di prox-mid RCA pada CAD 3 VD (inkomplet di LAD dan LCX), TAVB ec ACS on TPM, hematemesis ec stress ulcer, HAP, dan trombositopenia ec suspek ITP. Pasien dilakukan pemeriksaan laboratorium darah dengan hasil hemoglobin $12,4 \mathrm{gr} / \mathrm{dl}$, leukosit $14.080 / \mathrm{mm}^{3}$, trombosit $68.000 / \mathrm{mm}^{3}$, ureum $107 \mathrm{mg} / \mathrm{dl}$, kreatinin 2,3 mg/dl, kalium 3,1 mmol/L, kalsium 7,7 mmol/L, SGOT/SGPT 1968/2418 u/L, AGD arteri didapatkan asidosis metabolik terkompensasi. Terapi pasien ditambahkan dengan pemberian $\mathrm{KCl} 30$ $\mathrm{mEq}$, Ca gluconas $1 \mathrm{gr}$, dan terapi oksigen dengan RM 12 Ipm serta amiodarone dihentikan.

Rawatan hari ke-6, pasien tampak sesak semakin meningkat, kesadaran somnolen. Pemeriksaan fisik tekanan darah 103/62 $\mathrm{mmHg}$, denyut nadi 69 kali per menit, laju nafas 28 kali per menit, EKG di monitor tampak pacing. Pemeriksaan laboratorium 
didapatkan hemoglobin 10,8 gr/dl, leukosit $12.680 / \mathrm{mm}^{3}$, hematokrit 33\%, trombosit $44.000 / \mathrm{mm}^{3}, A G D$ arteri dengan kesan asidosis metabolik terkompensasi. Pasien diberikan bantuan nafas dengan bagging. Laju TPM diturunkan menjadi 30 bpm, irama masih pacing, lalu TPM dimatikan, tampak irama jantung PEA. Pasien dilakukan resusitasi jantung paru dan pemberian epinefrin setiap 3 menit serta dipersiapkan untuk intubasi. Setelah dilakukan resusitasi jantung paru selama 60 menit, intubasi dan pemberian bicnat $100 \mathrm{mEq}$, respon tidak ada. Keluarga pasien meminta untuk dihentikan resusitasi. Pasien dinyatakan meninggal dunia di hadapan keluarga dan perawat. Penyebab kematian pada pasien ini akibat henti jantung karena SKA dengan komplikasi perdarahan saluran cerna dan trombositopenia.

\section{PEMBAHASAN}

Intervensi koroner per kutan merupakan prosedur invasif jantung yang sering dilakukan untuk mengobati pasien dengan penyakit arteri koroner. Komplikasi yang menakutkan seperti diseksi koroner atau penyumbatan koroner akut pada era balon angioplasti telah banyak berkurang dengan ditemukannya stent arteri koroner dan penggunaan rutin terapi antiplatelet dan antitrombotik. Dalam praktik kardiologi intervensi kontemporer, diketahui bahwa perdarahan telah menjadi komplikasi awal yang paling umum terjadi terkait dengan intervensi koroner perkutan. Insiden perdarahan bervariasi menurut beberapa penelitian, data terakhir dari AS menemukan perdarahan mayor terjadi berkisar $1,7 \%$ setelah IKP, dimana sekitar setengahnya dari tempat akses arteri dan setengah lagi dari lokasi non akses, tersering pada saluran cerna. ${ }^{5}$ Data lain menyebutkan kejadian perdarahan mayor setelah IKP cukup signifikan, dengan angka kejadian perdarahan dalam 30 hari antara 0,7\%1,1\% pada pasien elektif, 0,6\%-4,7\% pada IMANEST dan 0,9\%-8,9\% pada IMAEST tergantung definisi yang digunakan. ${ }^{3}$

Penggunaan DAPT yang optimal setelah pemasangan DES masih belum jelas. Rekomendasi sebelumnya untuk DAPT setidaknya 3 bulan untuk sirolimus-eluting stent dan 6 bulan untuk paclitaxel-eluting stent tapi idealnya digunakan hingga 12 bulan. Peningkatan penggunaan DAPT tersebut meningkatkan risiko pasien untuk terjadinya cedera saluran cerna dan perdarahan. Risiko perdarahan saluran cerna cukup signifikan (1,3\%) dalam 30 hari terapi antiplatelet kombinasi dan cukup tinggi (12\%) pada populasi risiko tinggi dengan riwayat perdarahan ulkus peptikum. Penggunaan thienopyridine (ticaglerol) masih dalam penelitian lanjutan untuk pasien penyakit jantung koroner dengan perdarahan saluran cerna. Ticaglerol merupakan penghambat langsung dan reversibel reseptor platelet P2Y12, dimana SCH 530348 sebagai antagonis reseptor trombin. Data klinis yang tersedia sampai saat ini untuk masing-masing senyawa tersebut menunjukkan bahwa mereka memiliki 
profil keamanan dan kemanjuran yang menguntungkan pasien SKA yang menjalani IKP. ${ }^{7}$ Pada penelitian The Platelet Inhibition and Outcomes (PLATO), ticaglerol mempunyai angka perdarahan mayor terkait non-CABG yang lebih tinggi dibandingkan dengan clopidogrel, terutama setelah 30 hari penggunaan obat. ${ }^{4,8}$

Telah dilaporkan seorang pasien laki-laki 74 tahun dengan IMA-EST inferior onset 1 jam dengan AVB derajat II tipe I berubah ke irama junctional yang dilakukan pemasangan pacu jantung sementara dan tindakan intervensi koroner perkutan. Berdasarkan skor TIMI, risiko kematian dalam 30 hari pada pasien tersebut berkisar $\quad 0,7 \%$. Sedangkan risiko perdarahan pada saat rawatan menurut skor CRUSADE adalah risiko sedang dengan perkiraan perdarahan mayor sekitar $8,6 \%$. CRUSADE (Can Rapid risk stratification of Unstable angina patients Suppress ADverse outcomes with Early implementation of the ACC/AHA guidelines) merupakan skor perdarahan yang paling signifikan. Skor CRUSADE mempunyai tingkat sensitivitas dan spesifisitas untuk perdarahan mayor dan sedang selama perawatan adalah sekitar $77 \%$ dan 52\%. Perdarahan mayor merupakan komplikasi tersering setelah IKP primer dan berhubungan dengan peningkatan mortalitas dalam 1 tahun. $^{9}$ Selain itu, risiko perdarahan saluran cerna pada pasien ini juga diperberat akibat resusitasi jantung paru yang dilakukan pada pasien. Resusitasi jantung paru yang berhasil bisa menyebabkan efek samping yang berat. Hal ini dikarenakan tekanan yang tinggi selama kompresi dada dan pemberian terapi antikoagulan pada pasien jantung, maka komplikasi serius bisa terjadi, seperti perdarahan. ${ }^{10}$

Setelah dilakukan IKP primer yang sukses pada pasien ini, timbul komplikasi perdarahan saluran cerna, tetapi tidak terjadi penurunan hemoglobin yang signifikan. Hal ini menimbulkan suatu dilema. Mengobati pasien yang mengalami perdarahan setelah IKP merupakan suatu hal yang rumit, karena kita harus mempertimbangkan intervensi yang tepat untuk mengelola perdarahan aktif, untuk menimbang manfaat potensial untuk meneruskan atau menghentikan terapi antiplatelet dan untuk mengevaluasi apakah diperlukan transfusi sel darah merah yang bisa menimbulkan efek samping yang merugikan. ${ }^{4,5,7}$ Pedoman bersama American College of Cardiology, American Heart Association, dan Society for Cardiovascular Angiography and Interventions merekomendasikan bahwa terapi aspirin harus dilanjutkan seumur hidup pada semua pasien dengan IMA-EST, dan clopidogrel atau prasugrel harus diberikan paling sedikit 12 bulan pada pasien yang mendapat stent (BMS atau DES) selama IKP pada sindrom koroner akut. $^{2}$

Penggunaan UFH pada saat dilakukan IKP juga bisa menjadi penyebab perdarahan pada pasien. UFH merupakan anti trombotik indirek, yang berfungsi sebagai kofaktor untuk antitrombin, yang menghambat aktivitas thrombin dan faktor 
Xa, mempunyai waktu paruh di plasma darah sekitar 45-90 menit. Karena waktu paruh yang pendek, pengobatan ataupun pencegahan perdarahan bisa dilakukan dengan menghentikan pemberian UFH. Efek UFH secara cepat bisa dihentikan dengan pemberian protamin sulfat. Dosis protamin sulfat diberikan sesuai dosis UFH yang diberikan dalam 2 jam terakhir, dimana $1 \mathrm{mg}$ protamin sulfat akan menetralisir 80-100 unit UFH (maksimal 50 $\mathrm{mg}$ ), diberikan secara pelan $5 \mathrm{mg} /$ menit, dan memiliki waktu paruh 7 menit. ${ }^{11}$

Ticaglerol merupakan penyekat reseptor P2Y12 platelet secara langsung dan reversibel, dimana $\mathrm{SCH} 530348$ merupakan antagonis reseptor trombin. Pada beberapa penelitian, angka perdarahan yang mengancam nyawa lebih tinggi pada golongan antiplatelet novel (prasugrel dan ticaglerol) dibandingkan dengan clopidogrel. ${ }^{7,8,11,12}$ Setelah terjadi perdarahan saluran cerna pada pasien ini, dengan skor Rockal 6, diputuskan untuk menunda pemberian DAPT sambil terus memantau perdarahan yang terjadi setiap hari dan diberikan terapi drip lansoprazole dan sukralfat sebagai pelindung mukosa saluran cerna. Hal ini sesuai dengan algoritma tatalaksana perdarahan saluran cerna terkait pemberian DAPT setelah IKP. ${ }^{7}$ Setelah dilakukan evaluasi perdarahan, keesokan harinya dilanjutkan pemberian ticaglerol. Namun, 2 hari setelah pemberian ticaglerol, pasien kembali mengalami perdarahan saluran cerna, dan diputuskan untuk menunda kembali ticaglerol-nya, serta diberikan transfusi FFP
1250 cc. Hal ini sesuai dengan dosis terapi FFP untuk dewasa yang direkomendasikan sebanyak $15 \mathrm{cc} / \mathrm{kgBB} .{ }^{13}$ Penghentian terapi antiplatelet sangat penting tetapi reversal dari efek antitrombotik menjadi problematik. Efek antiplatelet tidak bisa dikembalikan dan ketika perdarahan berlangsung, transfusi platelet dibutuhkan. FFP bisa digunakan tetapi hanya bersifat volume expander dibandingkan dengan agen reversal. ${ }^{12}$ Bagaimanapun, FFP belum mempunyai bukti sebagai agen reversal antitrombotik selain warfarin. Sampai sekarang belum ada agen reversal spesifik untuk penghambat $\mathrm{P} 2 \mathrm{Y} 12 .{ }^{11}$

Menurut American Society for Gastrointestinal Endoscopy (ASGE), memulai kembali terapi antitrombotik boleh dilakukan jika risiko untuk tromboemboli lebih tinggi dari risiko perdarahan berulang. Ini berarti setiap kasus bersifat individual dan hal ini ditentukan oleh kesepakatan dari ahli jantung dan ahli saluran cerna, berdasarkan indikasi dan riwayat masingmasing pasien. Risiko perdarahan bisa dihitung dari skor Rockal, dimana skor $<2$ merupakan risiko rendah untuk terjadinya rekurensi dan skor >8 mempunyai risiko kematian yang tinggi. Sedangkan risiko trombosis akan meningkat jika terapi antiplatelet dihentikan. Hal ini misalnya pada risiko tinggi pasien dengan riwayat pemasangan stent intrakoroner (1 bulan untuk BMS, dan 6-12 bulan untuk DES) dan kejadian akut koroner dan akut serebrovaskular (3 bulan), risiko sedang pada pasien yang mengalami kejadian 
vaskular dalam 3 bulan atau operasi bypass aortokoroner, dan risiko rendah jika antiplatelet diberikan sebagai prevensi primer. $^{12}$

Rerata penghentian terapi antiplatelet dianjurkan tidak boleh melebihi 10 hari. Hal ini terkait dengan rerata umur platelet sekitar 7-10 hari, sehingga setelah 10 hari, >90\% platelet akan aktif kembali. Pada kasus dengan ticaglerol, dimana ikatan dengan reseptor $\mathrm{P} 2 \mathrm{Y} 12$ bersifat reversibel, sehingga platelet kembali aktif setelah penghentian yang lebih singkat (4-5 hari). Jika perdarahan terjadi setelah pemberian antiplatelet tunggal, dilakukan penurunan dosis, ganti dengan agen antiplatelet lainnya dan pemberian PPI merupakan pilihan yang tersedia. Jika perdarahan dengan DAPT, aspirin tetap diberikan dengan dosis minimal (80 mg sehari). Kombinasi aspirin dengan clopidogrel lebih aman dibandingkan dengan ticaglerol/prasugrel dan pemberian PPI direkomendasikan oleh panduan Amerika dan Eropa. ${ }^{1,12,14}$ Pemberian PPI dilakukan dengan regimen bolus omeprazole $80 \mathrm{mg}$, diikuti dengan drip $8 \mathrm{mg} / \mathrm{jam}$ selama 72 jam atau pemberian PPI dosis tinggi (pantoprazole $40 \mathrm{mg} 4$ kali sehari) juga bisa dilakukan. Hal ini masih menjadi perdebatan, manakah yang lebih superior untuk mengatasi perdarahan saluran cerna akut (Gambar 6). ${ }^{14,15}$

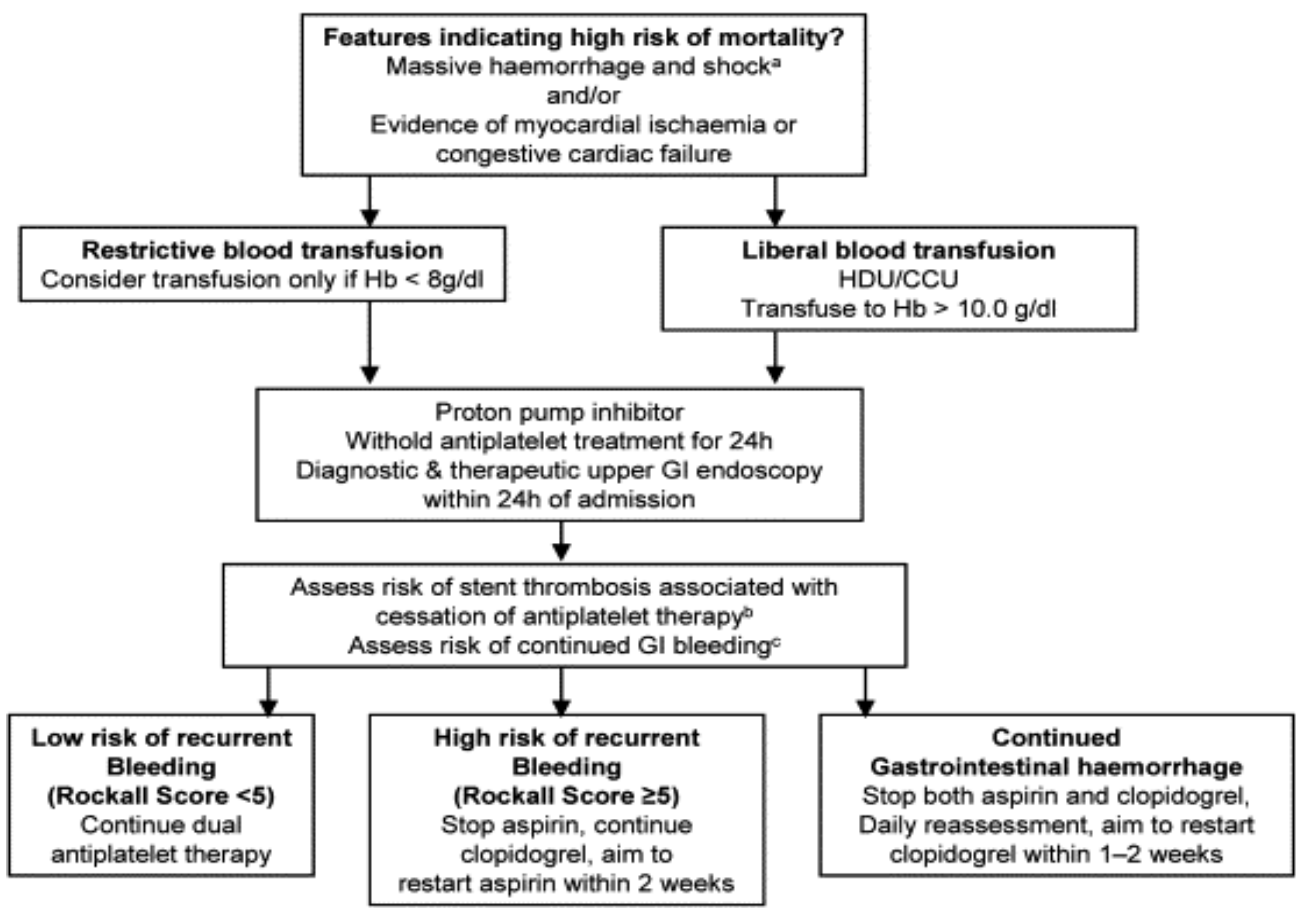

Gambar 6. Algoritma Tatalaksana Perdarahan GIT selama terapi ACS

Pada pasien yang mengalami perdarahan saluran cerna yang mendapat terapi antiplatelet, hemostasis endoskopi merupakan pilihan yang direkomendasikan untuk mengurangi angka morbiditas dan mortalitas. Pilihan hemostasis endoskopi diantaranya teknik injeksi menggunakan epinefrin atau etanol, terapi ablasi, koagulasi dengan forsep hemostasis, dan endoclips. ${ }^{2,7}$ 
Pasien juga mengalami trombositopenia, dimana turunnya trombosit sangat drastis dari $160.000 / \mathrm{mm}^{3}$ menjadi $84.000 / \mathrm{mm}^{3}$. Trombositopenia ini umumnya paling sering disebabkan oleh obat-obatan, sepsis, DIC dan TTP. Kerusakan endotel mikrovaskular sebagai mekanisme utama kerja dari obat tersebut. Sedangkan ticaglerol, yang bukan dari golongan thienopyridine, ticaglerol bekerja sebagai antagonis reseptor P2Y12-ADP yang reversibel, sehingga mekanisme untuk menyebabkan TTP masih dalam penelitian. Kasus TTP terkait ticaglerol biasanya terjadi dalam 1 bulan terapi. Tatalaksana TTP terkait ticaglerol sama dengan golongan thienopyridine lainnya, yaitu dengan penghentian ticaglerol sebagai terapi inisial dan pemberian plasma exchange merupakan terapi krusial untuk TTP terkait ticaglerol. Pemberian steroid bisa sebagai terapi pelengkap dan dilanjutkan selama 2 bulan. ${ }^{16,17}$ Oleh karena itu, penghentian pemberian ticaglerol merupakan pilihan yang tepat pada pasien ini. Namun, dengan dihentikannya pemberian ticaglerol juga berisiko terhadap peningkatan kejadian thrombosis pada pasien ini. Hal ini berefek buruk seperti yang digambarkan di bawah ini (Gambar 7). ${ }^{18}$

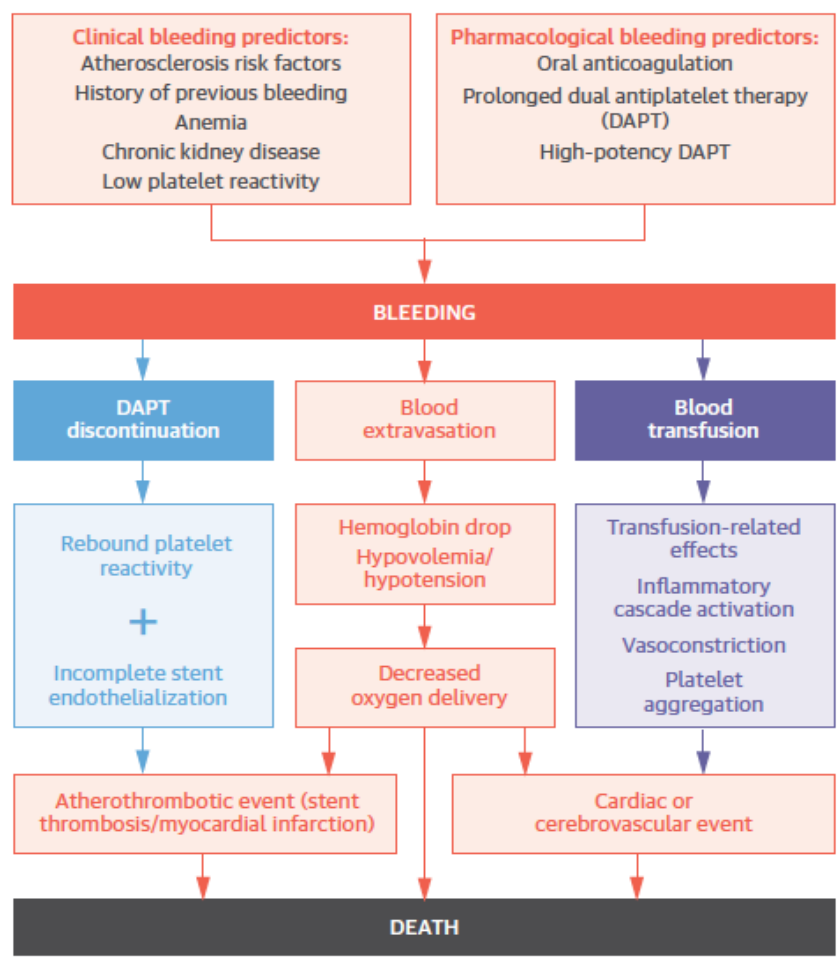

Gambar 7. Perdarahan setelah IKP: Prediktor dan Efek Perdarahan terhadap Mortalitas 


\section{SIMPULAN}

Peningkatan penggunaan terapi antiplatelet setelah IKP menyebabkan meningkatnya risiko perdarahan saluran cerna. Perdarahan setelah intervensi koroner menjadi isu mayor pada pasien dengan terapi antiplatelet. Strategi pencegahan termasuk menghindari penggunaan DES pada pasien yang berisiko tinggi untuk perdarahan saluran cerna. Penatalaksanaan perdarahan saluran cerna akibat penggunaan antiplatelet diantaranya transfusi darah, endoskopi dan mempertimbangkan kembali penggunaan terapi antiplatelet.

\section{UCAPAN TERIMA KASIH}

Ucapan terima kasih untuk Ketua Bagian Kardiologi dan Kedokteran Vaskular dan Ketua Program Studi IImu Penyakit Jantung dan Pembuluh Darah.

\section{DAFTAR PUSTAKA}

1. Nakabayashi K, Higashitani M. Control of acute phase intestinal bleeding after percutaneous coronary intervention by discontinuing dual antiplatelet therapy and implementing intra-aortic balloon pumping. J Cardiol Cases. 2015; 11:113-16. doi: 10.1016/j.jccase.2014.12.004.

2. Yasuda H, Matsuo $Y$, Sato $Y$, Ozawa S, Ishigooka S, Yamashita M, et al. Treatment and prevention of gastrointestinal bleeding in patients receiving antiplatelet therapy. World J Crit Care Med. 2015; 4(1):40-46. doi: 10.5492/wjccm.v4.i1.40.

3. Kwok CS, Rao S V, Myint PK, Keavney B, Nolan J, Ludman PF, et. al. Major bleeding after percutaneous coronary intervention and risk of subsequent mortality: a systematic review and meta-analysis. Open Heart. 2014; 1(1):e000021. doi: 10.1136/openhrt-2013-000021.

4. Chhatriwalla AK, Amin AP, Kennedy KF, House JA, Cohen DJ, Rao S V, et. al. Association Between Bleeding Events and In-hospital Mortality After Percutaneous Coronary Intervention. Jama. 2013; 309(10):1022-9. doi: 10.1001/jama.2013.1556.

5. Shuvy M, Ko DT. Bleeding after percutaneous coronary intervention : can we still ignore the obvious?. Open Heart. 2014; 1(1):e000036. doi: 10.1136/openhrt-2014-000036.

6. Mehran R, Rao SV, Bhatt DL, Gibson CM, Caixeta A, Eikelboom J, et. al. Standardized bleeding definitions for cardiovascular clinical trials: A consensus report from the bleeding academic research consortium. Circulation. 2011; 123(23):2736-47. doi: 10.1161/CIRCULATIONAHA.110.009449.

7. Tan VP, Yan BP, Kiernan TJ, Ajani AE. Risk and management of upper gastrointestinal bleeding associated with prolonged dual-antiplatelet therapy after percutaneous coronary intervention. Cardiovasc Revasc Med. 2009; 10(1):36-44. doi: 10.1016/j.carrev.2008.11.001.

8. Becker RC, Bassand JP, Budaj A, Wojdyla DM, James SK, Cornel JH, et. al. Bleeding complications with the P2Y12receptor antagonists clopidogrel and ticagrelor in the PLATelet inhibition and patient outcomes (PLATO) trial. Eur Heart J. 2011; 32(23):2933-44. doi: 10.1093/eurheartj/ehr422. 
9. Al-Daydamony MM, Farag EM. CRUSADE bleeding score as a predictor of bleeding events in patients with acute coronary syndrome in Zagazig University Hospital. Indian Heart J. 2016; 68(5):632-38. doi: 10.1016/j.ihj.2016.03.007.

10. Buschmann $\mathrm{CT}$, Tsokos M. Frequent and rare complications of resuscitation attempts. Intensive Care Med. 2009; 35(3):397-404. doi: 10.1007/s00134-008-1255-9.

11. Makris M, Veen JJ Van, Tait CR, Mumford AD, Laffan M. Guideline on the management of bleeding in patients on antithrombotic agents. Br J Haematol. 2013; 160(1):35-46. doi: 10.1111/bjh.12107.

12. Pipilis A, Makrygiannis S, Chrisanthopoulou E, Sourlas N, Kaliambakos S, Ntailianas A. Gastrointestinal bleeding in patients receiving antiplatelet and anticoagulant therapy: Practical guidance for restarting therapy and avoiding recurrences. Hellenic J Cardiol. 2014; 55(6):499509.

13. National Blood Tranfusion Committee. Fresh Frozen Plasma (FFP) Dosage. JPAC. Accessed from: https://www.transfusionguidelines.org/transfusion-handbook/4-safe-transfusion-right-bloodright-patient-right-time-and-right-place/4-13-transfusion-of-blood-components

14. Kim BJ. Management and Prevention of Upper GI Bleeding. Gastroenterol Nutr. 2011; 7:1-20.

15. Worden JC, Hanna KS. Optimizing proton pump inhibitor therapy for treatment of nonvariceal upper gastrointestinal bleeding. Am J Health Syst Pharm. 2017; 74(3):109-16. doi: 10.2146/ajhp151032.

16. Siao WZ, Chuang WY, Su CH, Huang SF, Tu WK, Chan KC. A Rare Case of Ticagrelor-Induced Profound Isolated Thrombocytopenia. Acta Cardiol Sin. 2017; 33(5):556-58.

17. Doğan A, Özdemir B, Bal H, Özdemir E, Kurtoğlu N. Ticagrelor-associated thrombotic thrombocytopenic purpura. Anatol J Cardiol. 2017; 17(1):73-74. doi: 10.14744/AnatolJCardiol.2017.7426.

18. Généreux P, Giustino G, Witzenbichler B, Weisz G, Stuckey TD, Rinaldi MJ, et. al. Incidence, Predictors, and Impact of Post-Discharge Bleeding After Percutaneous Coronary Intervention. J Am Coll Cardiol. 2015; 66(9):1036-45. doi: 10.1016/j.jacc.2015.06.1323. 